\title{
Scientific American.
}

EXPLORATIONS IN PATAGONIA.

The interest of the scientific world in the extinct life

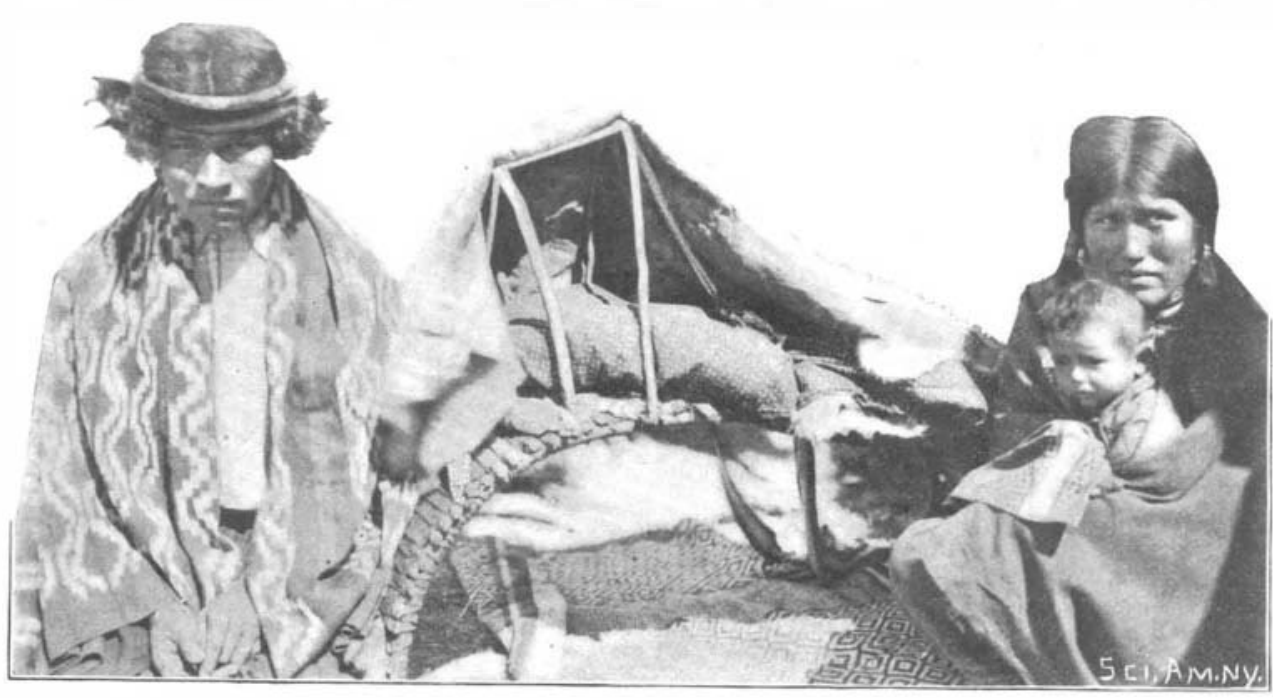

Tehnelche Man, Squaw, and Child. of Patagonia dates from the publication in the early forties of the reports of Owen and Sowerby on the col-

ing, in so far as possible, a detailed study of the eolocy of that region, sufficient at least to determine the exact sequence and relations of the different horizons, and of securing all data possible which might zons, and of securing all data possible which might
prove of use in correlating South American rocks with those of North America and Europe.

Since no one else dertake this work, early in the autumn of 1805 the writer de cided to attempt it in behalf of the department of paleontology of Princeton University. Dr. W. B. Scott heartily approved of the plan when it was presented to him, and freely gave his energy and influence toward its a c complis hment, while from several friends and alumni of $\mathrm{t} h \mathrm{e}$ institution came most essential lections of fossil vertebrates and invertebrates made in that region by Darwin during the voyage of the "Beagle," from 1833 to 1836.

Notwithstanding the interesting and unique nature so entirely different from everything known in the northern hemisphere, yet the interest aroused by his discoveries was permitted to subside, and for many years almost nothing was done toward bringing to light the exceedingly rich extinct fauna of this distant and little known land. this region by the explorations of Moyano, Moreno, Burmeister, Lister, and other tained by each of these expeditions, they were really insignificant from a paleontological thand wint as con insignifeant frem a paleontological stand pared with the brillant achieverients of Charles an two brothers will a testimony of what men endowed with an enthusiasti zẹal for their profession may accomplish even under most discouraging circumstances.

The beginning of the first systematic investigation of the paleontology of Patagonia dates from the first a series of papers written by Dr. Fiorentino Aur thin upon material collec almost invariably announcing discoveries more remarkable than the preceding.

The discoveries announced by the Ameghinos wer clusions drawn from them were so extraordinary and frequently so opposed to conclusions believed to be well established by observed facts in the northern as to the desirability of bringing together a representative collection of fosil vertebrates and invertebrates frou chat region for study and couparison with collections from North America and Europe and of makof most of the fossil mammals in Darwin's collection,

During the eighties interest was again attracted to

Interesting and important as were the results attwo brothers will always stand as a monument to South American paleontology and as a substantia voyage of Charles Ameghino in 1887. Since that time have followed one another in rapid succession, each of such an interesting nature, and many of the conhemisphere, that paleo'itologists everywhere agreed financial assistance. So that by March 1, 1896, I was able to sail with Mr. $\bullet$. A. Peterson on our hirst expedicontinued with but occasional interruptions.

It would be quite beyond the limits of this article to give in detail the results of the work so far accomplished or to discuss any of the m a n y controverted questions relating to the geology of tha portion of South America. A brief account of the physiographic, geologic, a n d paleontologic features of the region, together with a summary of the mine important win:ults $v$. the work $\leadsto$ tal a complishea, may be of interest to readers of the ScIENTIFIC AMERICAN.

Physiographically, Patagonia is divided into two sharply defined regions--an eastern level and comparatively barren plain and a western exceedingly broken and moun. tainous region. The former extends east-

ward from the base of the Andes, where it has an altitude of 3,000 feet to the Atlantic coast, where it terminates in a contiun

400 feet in height.

Three distinct features characterize the topography and tend to relieve the monotony of the broad Pataanian plains. The first of these is the series of esarpments, from a few feet to several hundred in height encountered at successive altitudes as one proceeds from the coast inland toward the Andes. The escarpments have a present coast line, and they doubtless mark successive stages in the final elevation of the land above the sea. The second feature is to be seen in the series of deep transverse valleys crossing the territory from east to west and constituting the present drainage system. In so far as my observations have gone, these are all true valleys of erosion. The third and perhaps most striking feature in the topography of eastern Patagonia are the volcanic cones and dikes, and the result ing lava sheets, which, covering extensive areas throughout the central plains, are seen capping most of the higher table lands and frequently descending well down the slopes into the present valleys, while the extinct volcanoes of ten rise majestically hundreds of feet above the surrounding plain

In a line approximating the seventy-second meridian of west longitude, the Andes rise abruptly frow the plains and form one of the most rugged and in many respects most picturesque mountain chains in the world. Many of the peaks attain an altitude of over 10,000 feet, quite sufficient at this latitude to precipitate most of the moisture in the atmosphere as it is forced over them from the Pacific. Owing to the southwesterly winds which prevail kere throughou the year, the atmosphere during its long journey across the Pacific becomes saturated with moisture, which, together with the completeness of the precin

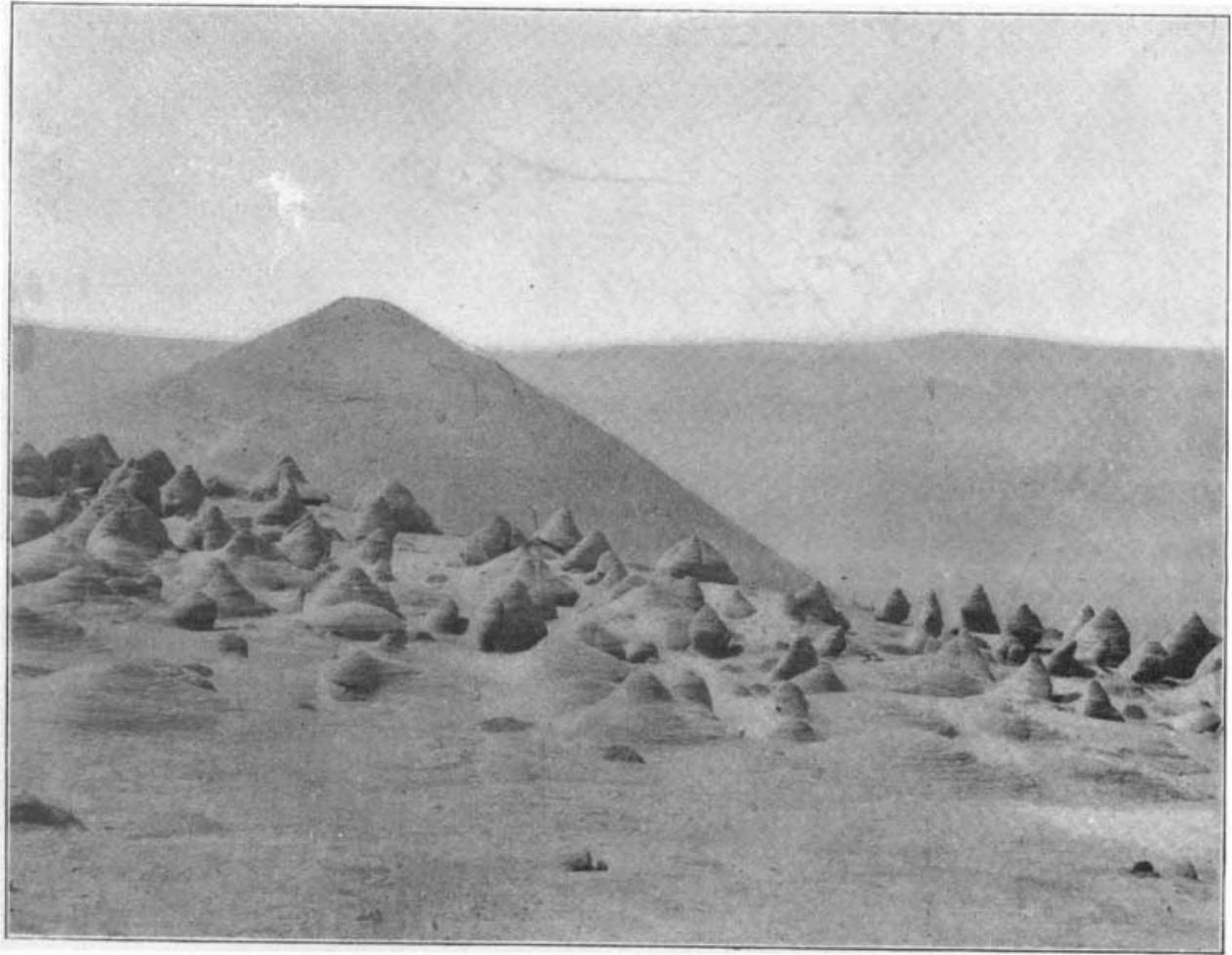

Curious Wind and Rain Erosion in Andes of Patagonia tation brought about by the advantageous topography of the western coast, renders this region one with an exceedingly high annual rainfall and consequently luxuriant vegetable orowth in striking contrast to the dry and comparatively barren eastern region, where the winds, already deprived of most of their moisture during their passage over the Andes, are usually dry and the annual rainfall correspondingly low. The prevailing winds in eastern Patagonia, as in western, are southwesterly, and an easterly wind of twenty-four hours' duration on the eastern coast is sure to terminate in a heavy fall of rain or snow.

Not all the moisture of the mountainous region is precipitated as rain, for in the higher Andes severe snowstorms prevail throughout the entire year, ample for the formation of great ice fields, from which ex. tend numerous glaciers, many of "which reach from the mountain summits far down below timber line, and some on the western slope quite into the sea. Formerly these glaciers were much more extensive than at present, and they doubtless contributed to the erosion of the exceedingly intricate system of mountain gorges and fiords now forming so conspicuous a feature of the region.

The slopes of the Andes below an altitude of 3,000 feet are covered with dense forests, especially on the western side. The variety of trees in the southern regions is very limited, and the quality of the wood for lumber or timber for building is poor. Two species of beech. Fagus antarctica and F. betutoides, the latter an evergreen, are much the commoner of the trees. The deciduous beech is especially abundant, and is the only tree found throughout extensive areas on the eastern slopes of the Andes.

Within the dense forests, lichens, ferns, mosses, and other cryptogams grow in great profusion, entirely covering the rround and trunks and lower branches of the trees. The delicate foliage and variety and har- 


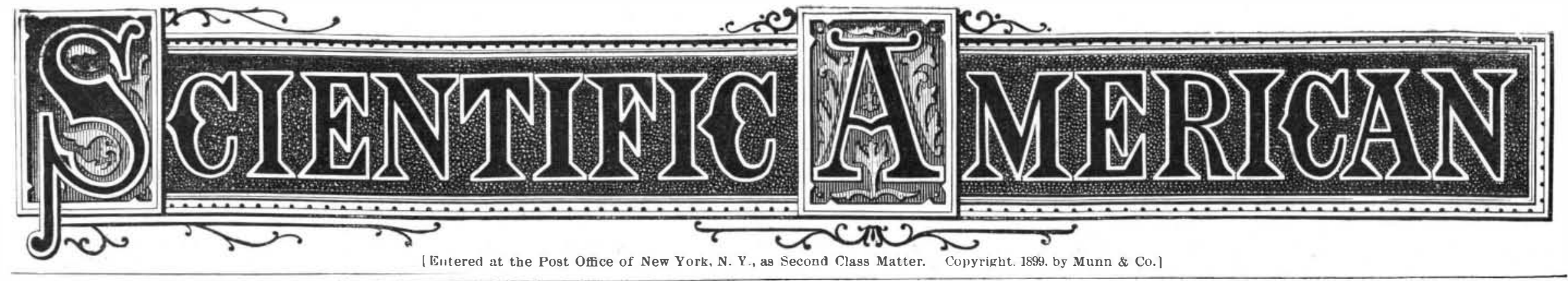

A WEEKLY JOURANA OF PRACTICAL INFORMATION, ART, SCIENCE, MECHANICS, CHEMISTRY, ANI MANUFACTURLS. Vol. NEW YORK, NOVEMBER 18, 1899. $\underset{\text { WEEKLY. }}{\$ 3.00}$ A XEA R.

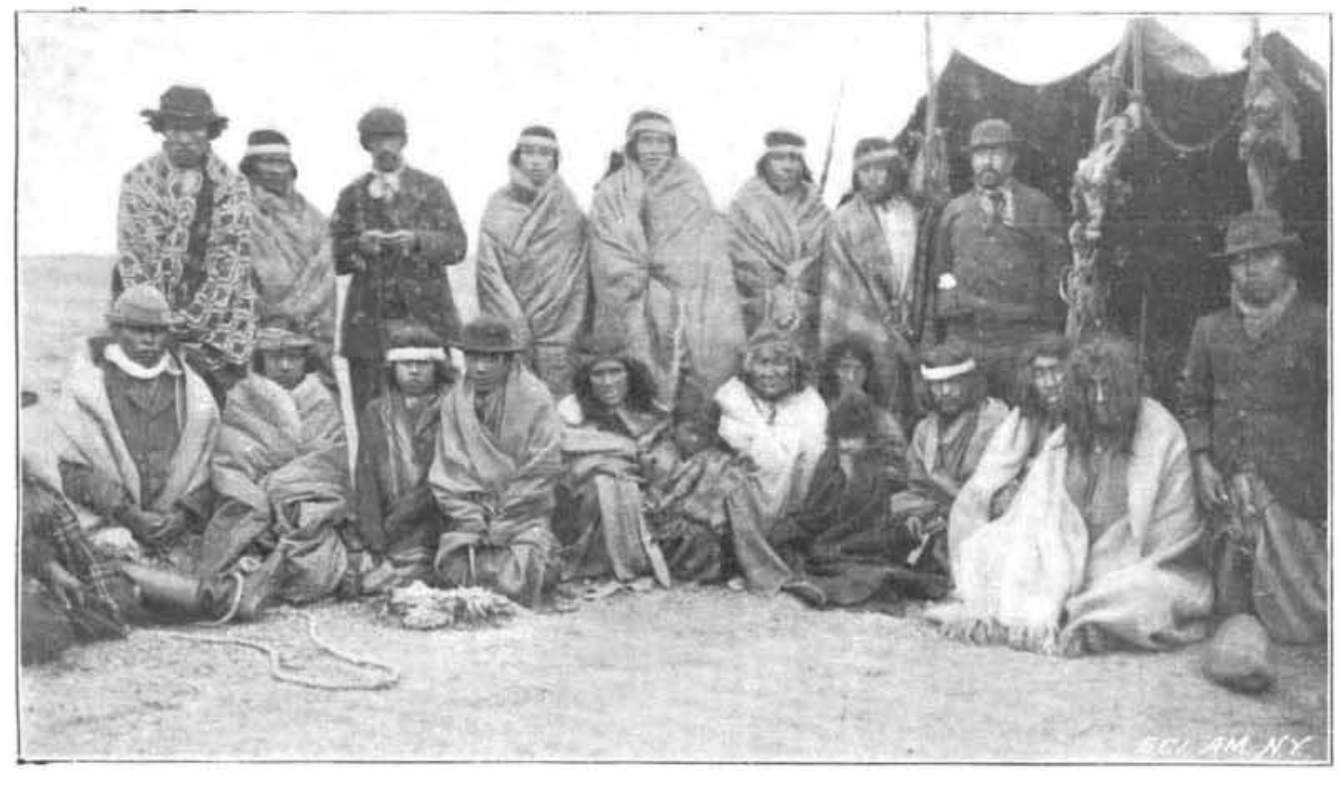

Group of Tehnelches with Two White Axgentines.

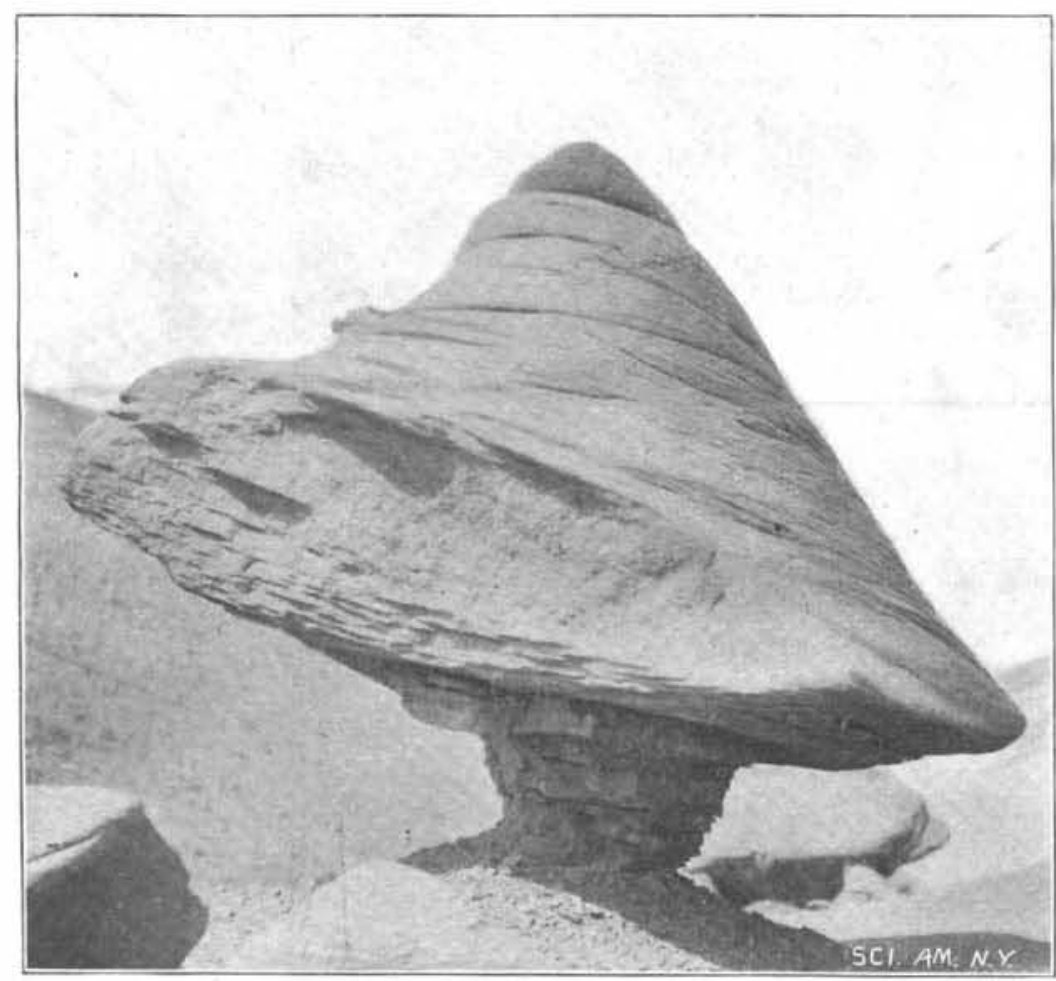

Balancing Rock Due to Erosion.

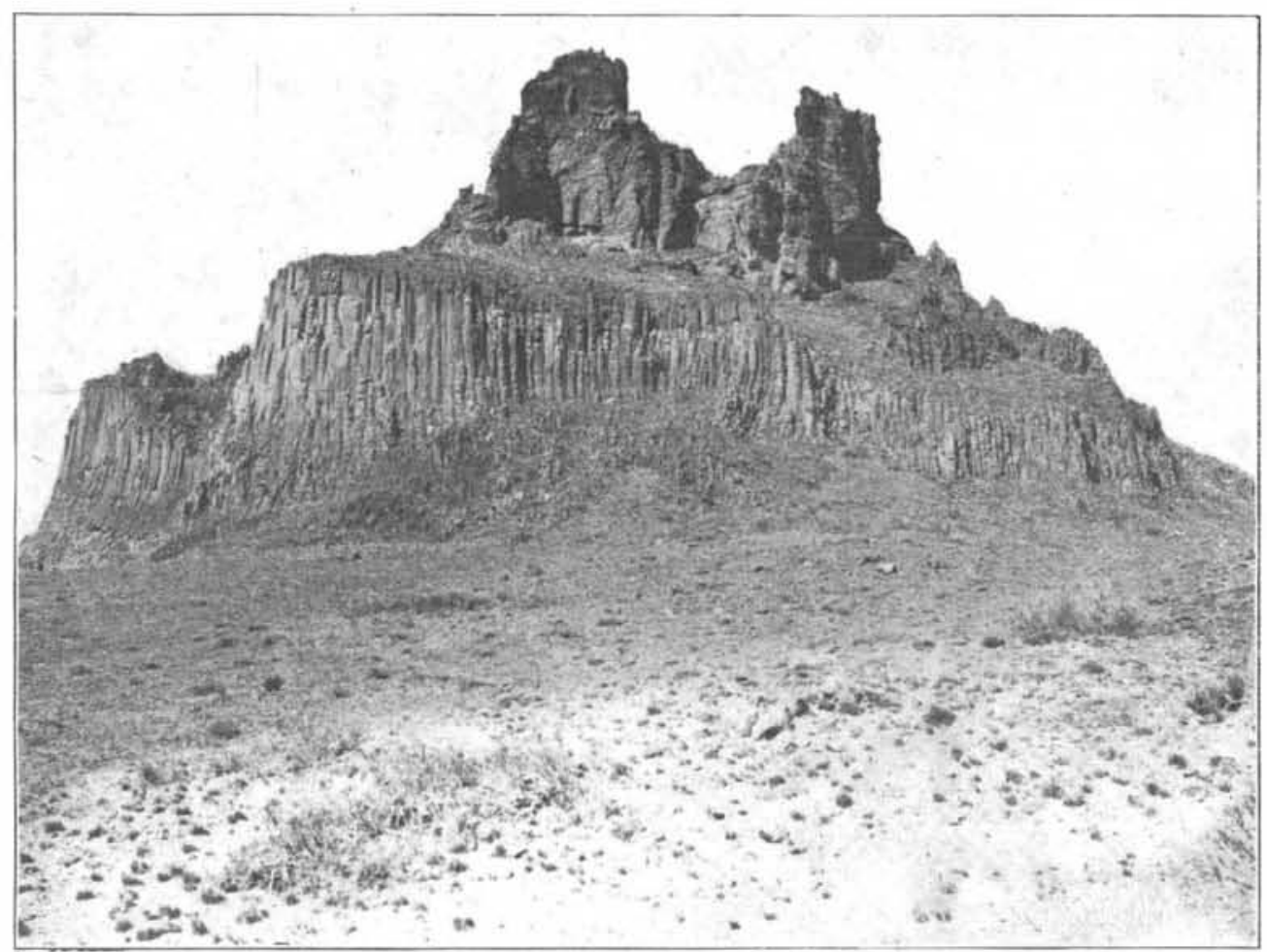

Extinct Volcano, Plains of Patagonia.

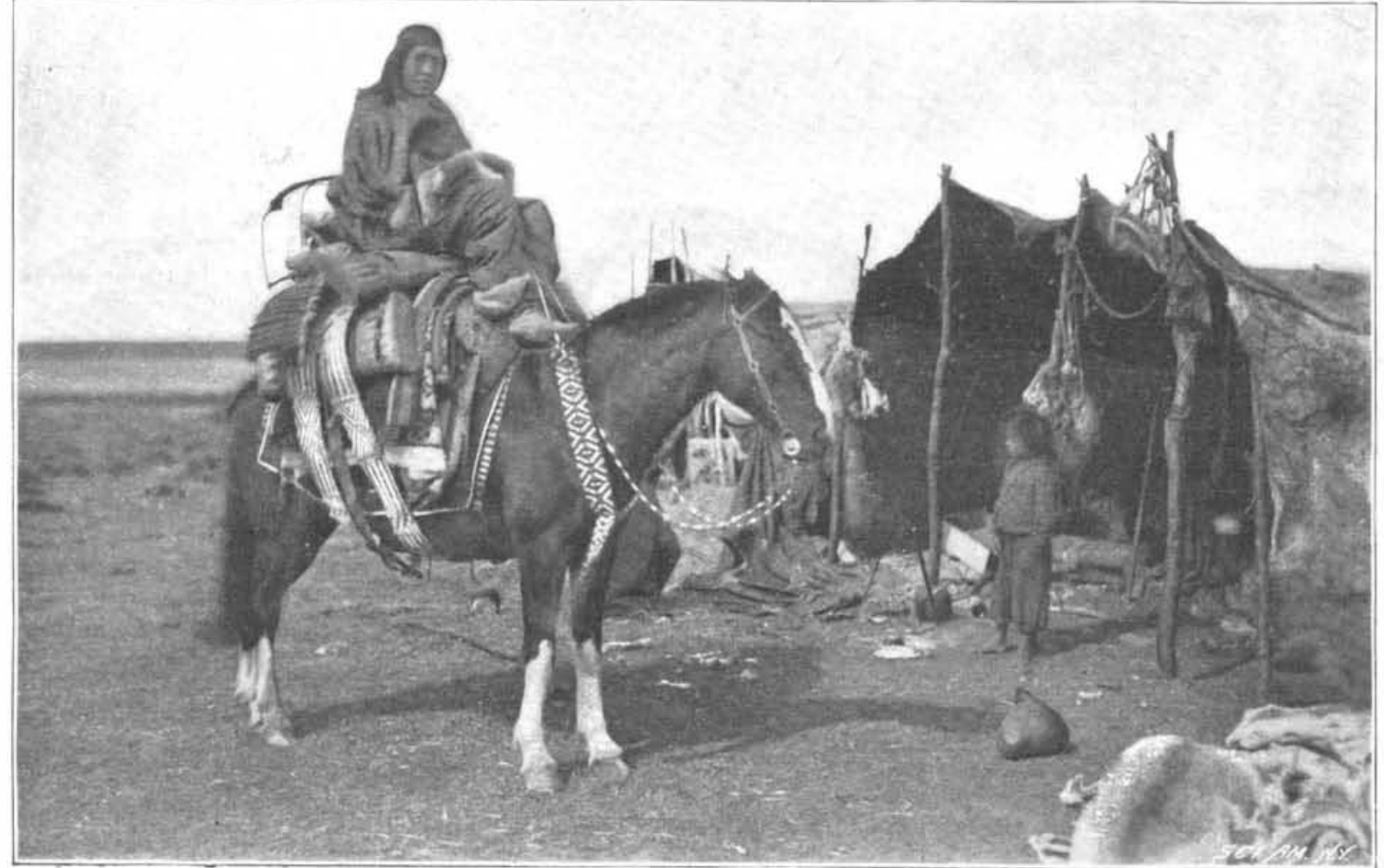

Indian Woman Ready for the March.

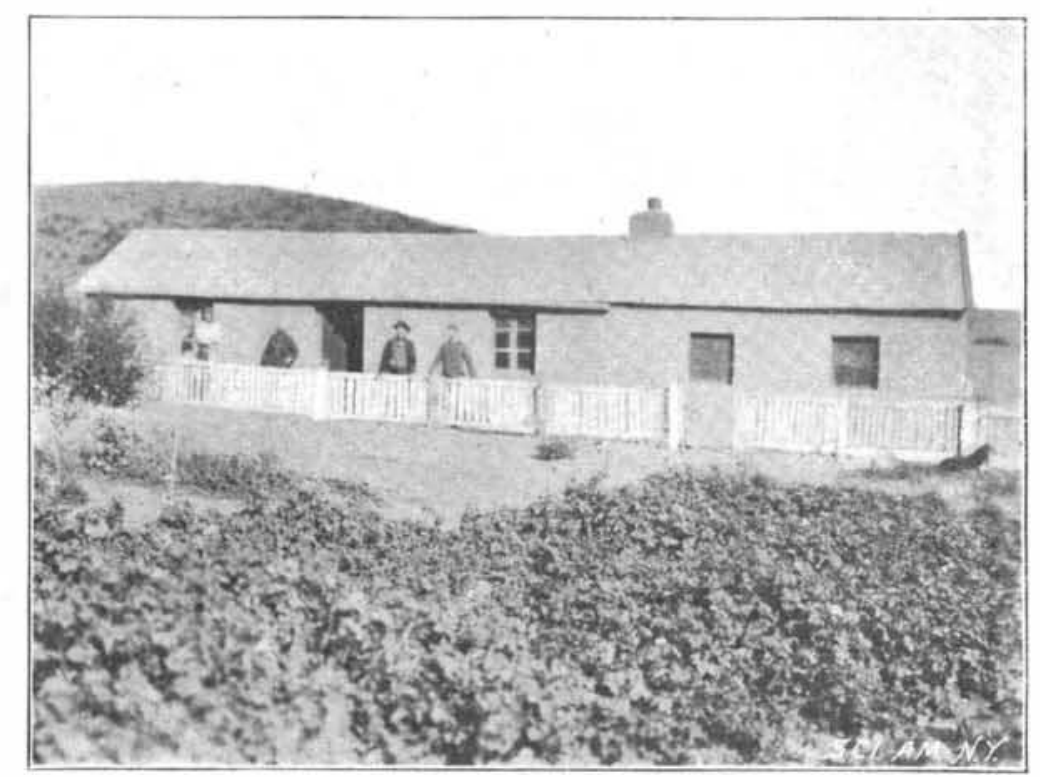

A Sheep Farmer's House in Patagonia.

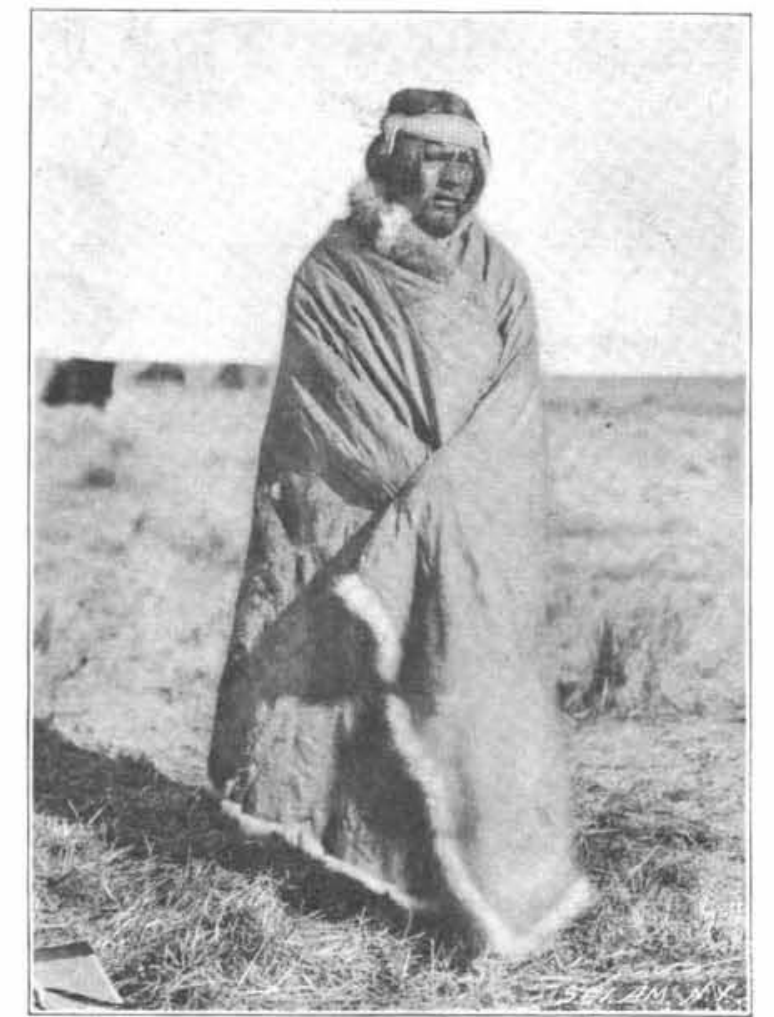

An Old Tehnelche

PROF. HATCHER'S EXPLORATIONS IN PATAGONIA UNDER THE AUSPICES OF PRINCETON UNIVERSITY.- [See page 328.] 
mony of colors of these plants, always freshened by frequent showers, enhance the other natural beauties of this region, and give to the quiet depths of the forests a peculiar attractiveness, contrasting strongly with the rugged cañons and serrated crests of the higher Andes.

The most conspicuous animals of the forest region are a small deer, not quite so large as our Virginia deer, the male with usually only two points on either horn. The puma, or mountain lion, is abundant both on the plains and in the mountains. There are two species of dogs. The larger, Canis magellanicus, is about the size of a small collie, of a reddish brown color, and frequents the wooded regions. It is rather shy, in striking contrast with the smaller C. azare, abundant in the plains, of a light gray color, and about the size of a small red fox. The guanaco or South American camel is very abundant over the plains, and occasionally enters the wooded mountaino us districts. Among the birds, two, from their size, are especially n o t e w orthy, the rhea, or socalled ostrich, called ostrich, found in great $\mathrm{nu}$ mbers on the plains, and the condor, Andes, along Andes, along the high bluffs of the sea coast and about the basalt cliffs of the interior plains region.

The natives

of the eastern a nd western regions belong to two entirely distinet races, differmg from each other in their customs, language, and language, and mode of life. To the eastern region belong ches, a large, well developed, and peaceable race, living entirely by the chase. They construct their h a bitations and make their mple clothing ample clothing with consider able skill from the skins of the guanaco. In the capture of the guanaco, rhea, and other ganie animals and birds they are exceeding are exceeding ly proficien much ingenu-

The Channe Indians of the western region are physically

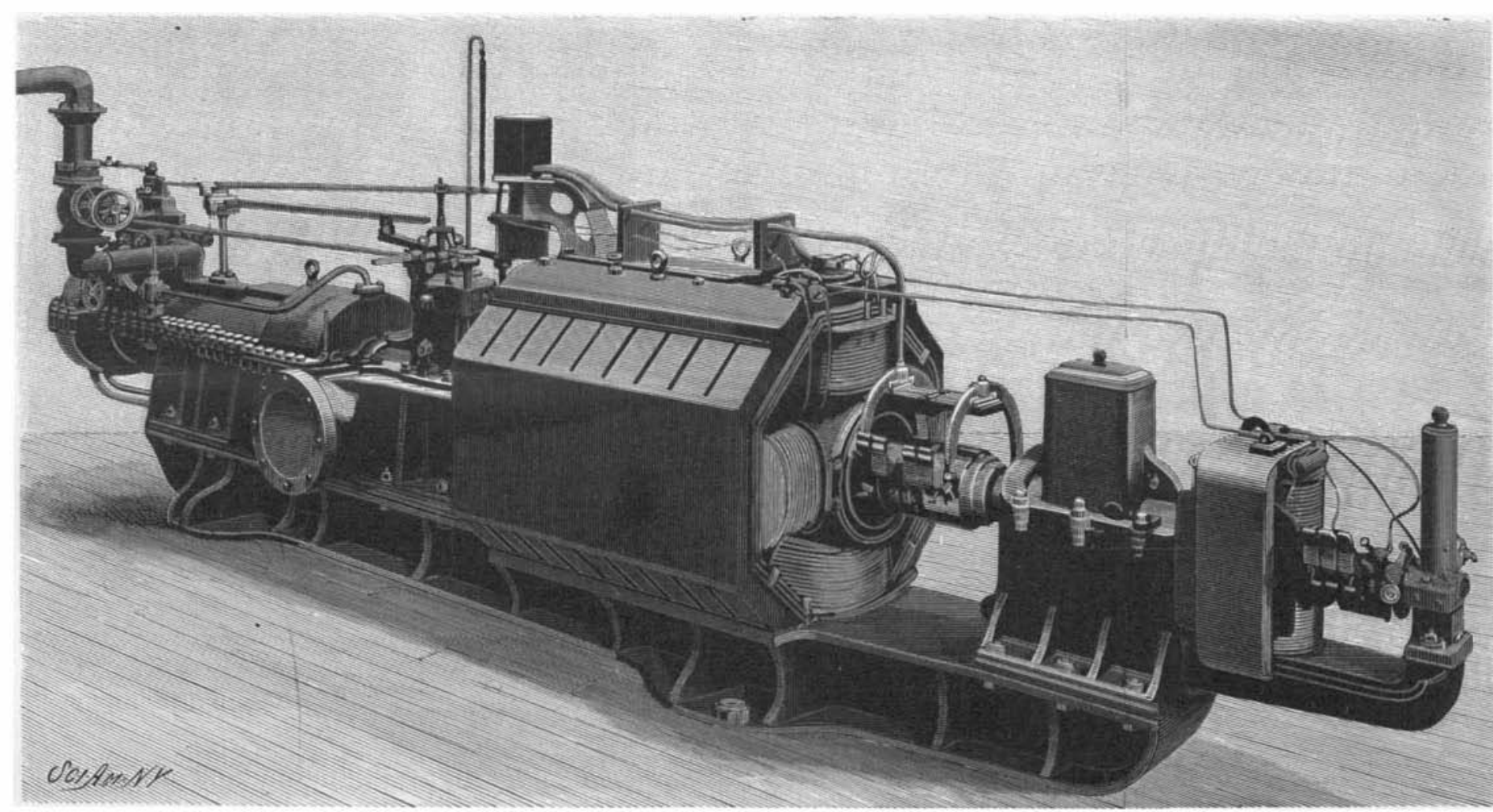

75-KILOWATT TORBO-GENERATOR AT THE HOTEL CECIL, LONDON.

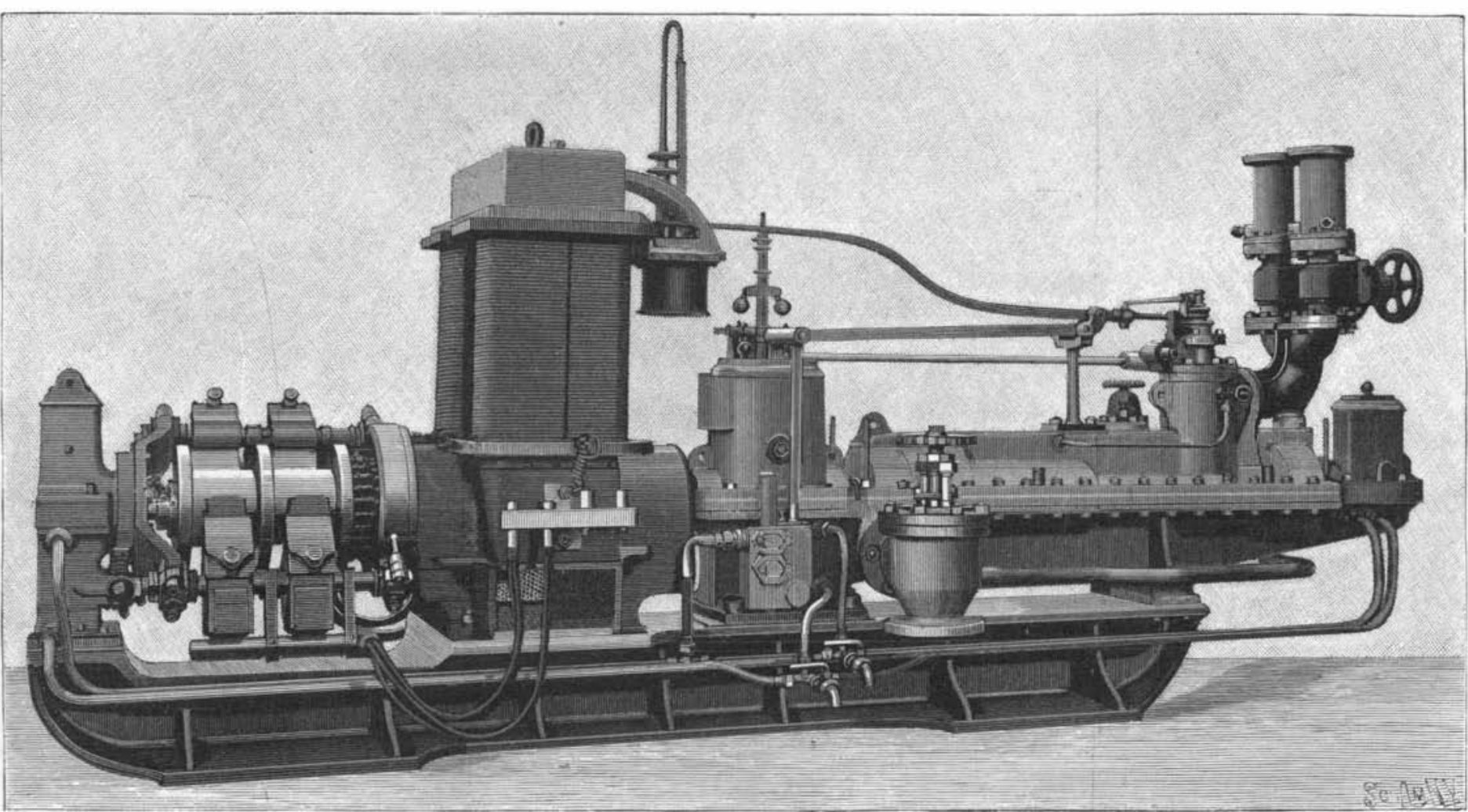

350-KILOWATT TURBO-ALTERNATOR AND EXCITER AT THE METROPOLITAN ELECYRIC SUPPLY COMPANY'S STATIONS.

the North American fauna would indicate a long period of isolation of the two Americas, continuing until comparatively recent tertiary times.

\section{THE PARSONS STEAM TURBINE.}

Although the Parsons steam turbine is identified in the public mind with high-speed torpedo boats, it is a fact that long before the "Turbinia" made her phenomenal speeds the Parsons turbines had been doing highly successful work on land, more particularly in connection with electric light and other electrical installations.

The Hon. Charles Parsons is the son of the late Earl of Rosse, whose great telescope, erected on his estates in Ireland, has long been one of the scientific landmarks of the age. His first successful invention was an epicycloidal encine, in which the cylinders revolve on a abled a perfect balancing of the m•ving parts to be obtained with a resulting highspeed rotation, and in this respect the invention uay be regarded as forestalling forestalling the present de. speed engines. In $1884 \mathrm{Mr}$. Parsons commenced the de signing of a compound steam turbine and a dynamo with a work ing a work ing speed of tions per mintions per min-
ute. The preliminary experiments showed the necessity for bearings that should be somewhat elastic, and to meet the case the the case the form of bear ings $\mathrm{s} h$ ow 1 Fig. 1 was de signed. It consists of a gun metal tube in which the shaft is rotated, and on this $\mathrm{t} a \mathrm{be}$ a $\mathrm{re}$ tabe are washers which are alternatel. $\mathrm{larger}$ and smaller in size, t h e smaller ones fitting the bush and the larger ones for the metal standard of the bearing. The bearing. The whole series of pressed tightly together by a spiral spring and a nut on the bush; one wider washe

much inferior to the Tehnelches. They are essentially a maritime people with all their activities clustering about the shore, from which they never proceed more than a few miles inland. They subsist chiefly upon shell fish. the flesh of seals, fish, and the sea otter and a few edible fungi indigenous to the region they inhabit. From the skins of the seal and sea otter they construct their ciothing, usually exceedingly scanty, notwithstanding the inhospitable climate. Rude huts are sometimes built from the branches of trees, but they spend much of their time in small open boats made of beech bark sewed together with whale bone. It is in the construction of their boats and the implements used by them in the capture of seals that they show greatest skili and resource.

Although the plains of eastern Patagonia are exceedingly monotonous and uninteresting to the casual observer, yet they are of the greatest interest to the geologist and paleontologist, for it is the rocks composing entirely distinct from anything then living in the

While there is a striking and universal dissimilarit between this fauna and that of the northern hemspere, on the other hand there are many apparently close resemblances between the extinct Patagonian fauna and the recent Australian fauna. The same is also true, though in a more restricted sense, of this fauna and that of South Africa. The explanation of these similarities and dissimilarities in the faunas ot the various regions can be best explained by assumin that they indicate in the one case a direct relationship and in the other a totally distinct origin for each. The relations apparently existing between this Patagonian fauna and certain form now living in Patagonian fauna and certain forms now living in haps, by way of an Antaretic continent permittin haps, by way of an Antaretic continent permitting
of an intermigration of species. The dissimilarity in which is threaded on last fits both bush and standar and forms a fulcrum, with the result and when the shaft deflects a certain amount of by the shaft itself, though the washers restrict the anplitude of vibration and bring the running to steady rate about the principal axis of the rotating mass.

This form of bearing was abandoned in 1890 in favo of the simpler arrangement shown in Figs. 2 and 3 . I consists of three concentric tubes of brassor steel fit ting easily within each other, the oil between the tubes forming a self-centering cushion which has a considerable effect on the vibrations of the shaft. The tubes answer the purpose of the separate washers in the older form of bearing, with the added advantage that the tubes show no sign of wear, the all filu between then being preserved under all conditions of service.

The first successful steam turbine dynamo was constructed in 1885. It was operated at a speed of 18,000 